\title{
The influence of tissue spatial geometry and functional organisation on liver regeneration
}

\author{
Luigi Aloia \\ MRC Laboratory for Molecular Cell Biology, University College London, Gower Street, London WC1E 6BT, UK
}

\section{A R T I C L E I N F O}

\section{Keywords:}

Liver regeneration

Fibrosis

YAP

Liver progenitors

Organoids

Tissue geometry

\begin{abstract}
A B S T R A C T
The adult liver exerts crucial functions, including nutrient metabolism and storage, bile production and drug detoxification. These complex functions expose the liver to constant damage induced by toxins, metabolic intermediates and oxidative stress. However, the adult liver exhibits an exceptional regenerative potential, which allows fast and efficient restoration of tissue architecture and function both after tissue resection and toxic damage. To accomplish its vital role, the liver shows a peculiar tissue architecture into functional units, which follow the gradient of oxygen and nutrients within the parenchyma. Much less is known about the influence of tissue spatial geometry and functional organisation on adult liver regeneration. Here I examine the experimental evidence in mouse models showing that the spatial organisation of the epithelial and mesenchymal compartments plays a key role in liver regeneration and favours the establishment of regenerative adult liver progenitors following liver injury. I also discuss the advantages and limitations of human and mouse 3D hepatic organoid systems, which recapitulate key aspects of liver function and architecture, as models of liver regeneration and disease. Finally, I analyse the role of the YAP/TAZ transcriptional co-activators as a central hub sensing the extracellular matrix (ECM), metabolic and epigenetic remodelling that regulate liver regeneration and promote liver disease, such as fibrosis, chronic liver disease and liver cancer. Together, the findings summarised here demonstrate that local physical and functional cellular interactions determined by the liver peculiar spatial geometry, play a crucial role in liver regeneration, and that their alterations have important implications for human liver disease.
\end{abstract}

\section{Introduction}

The adult liver is the largest internal organ of the body and exerts crucial functions, including nutrient metabolism and storage, regulation of blood glucose levels, synthesis of plasma proteins, bile production and drug detoxification. To achieve these key functions, the adult liver has peculiar tissue structure and geometry, which allow efficient nutrient and oxygen distribution across the liver parenchyma [1-3]. Nutrients are supplied by the portal vein, which connects the liver to the gastrointestinal tract. Oxygenated blood is supplied by the hepatic artery. Biliary ducts collect the bile and export it to the duodenum for digestive purposes. Portal vein, hepatic artery and biliary ducts form the so-called portal triad. The central vein returns poorly oxygenated and metabolite-rich blood to the systemic circulation. Thus, oxygen and nutrient-rich blood flow from the portal triad to the central vein, creating a gradient of oxygen and nutrients within the liver parenchyma, whereas the bile flows in the opposite direction. The spatial distribution of the central vein and portal triad defines the liver tissue spatial and functional organisation [1] (Fig. 1). The basic histological unit of the liver is the lobule, which has a hexagonal shape, with the central vein in the middle and portal triads located at each corner. The minimal functional unit of the liver is the acinus. The acinus has an irregular shape, which results from the intersection of two adjacent lobules and is aligned around the veins. The acinus is centred around the portal triad and is divided into three zones, which follow the decreasing gradient of nutrient and oxygen from the portal triad (zone 1) to the central vein (zone 3) [1]. At the cellular level, the adult liver is composed of two epithelial cell types, hepatocytes ( $\sim 60 \%$ of total liver cells) and cholangiocytes (3-5\%), mesenchymal cells, including hepatic stellate cells (HSCs) ( $\sim 8 \%)$, resident macrophages, called Kupffer cells $(\sim 15 \%)$, and endothelial cells (15-20\%) [1-3] (Fig. 1).

Due to its key function, the adult liver is constantly exposed to damage caused by toxins, oxidative stress and intermediate metabolites. Importantly, the adult liver exhibits excellent regenerative potential both after resection of $70 \%$ of its mass (also known as partial hepatectomy) and following toxic damage [4]. This is even more remarkable considering that the adult liver is a slowly self-renewing organ and lacks an evident stem-cell compartment in homeostasis, opposite to other highly regenerative organs such as intestine, stomach and skin. Thus, cellular plasticity awakens liver cells in response to damage and induces 
cell-fate changes, such as cell trans-differentiation and de-differentiation into progenitors, to achieve efficient liver regeneration [5-8]. However, persistent liver injury, caused by alcohol abuse, metabolic dysfunctions, severe obesity and viral infections, overwhelms liver regenerative capacity and impairs liver function, causing chronic liver disease and predisposing to liver cancer [9].

Liver organoid systems have recently emerged as reliable models of liver regeneration and disease [10]. Here organoid systems are defined as 3D self-organising structures, which recapitulate aspects of the native tissue architecture and function, in agreement with the guidelines established by the hepatic, pancreatic and biliary (HPB) Organoid Consortium [10].

Increasing evidence indicates that the spatial geometry and tissue architecture not only allows the efficient accomplishment of liver function, but also influences liver regenerative capacity in response to tissue resection and toxic damage. In this review, I examine the experimental evidence showing the influence of adult liver epithelial and mesenchymal spatial organisation in liver injury-response and regeneration in mouse models. In addition, I discuss the advantages and limitations of 3D hepatic organoids to recapitulate liver tissue geometry and model liver regeneration and disease. Finally, I examine the implications of ECM deposition and fibrosis, and the central role of the YAP/ TAZ-mediated signalling, in adult liver regeneration mediated by adult liver progenitors and human liver disease, such as fibrosis, chronic liver disease and liver cancer.

\subsection{Hepatocyte functional organisation and spatial geometry in liver regeneration}

Hepatocytes represent $\sim 60 \%$ of total liver cells and play a major role in liver regeneration [11-13]. They are crucial for nutrient metabolism and storage, exert detoxification functions, and produce the bile. Hepatocytes have specialised metabolic and drug detoxification competence according to their location in proximity to either the central or the portal vein. This so called zonation is consistent with the gradient of oxygen and nutrients within the lobule [1]. Hepatocytes show a multipolar organisation, which is dependent on ECM interactions, cell-cell adhesion and cytoskeleton architecture [14,15]. The apical domain defines contiguous lumina, which form a network of bile canaliculi that converge into biliary ducts. On their basal side, hepatocytes face the sinusoids, which are fenestrated capillaries showing a discontinuous endothelium to allow the exchange of nutrients and metabolites with the bloodstream. This is facilitated by the absence of a dense basal lamina $[14,15]$. Sinusoids influence the orientation of division of the hepatocytes [16]. Alterations of the mechanical homeostasis determined by the blood flow in sinusoids play an important role in liver regeneration [17].

Partial hepatectomy leads to a coordinated cellular response and significant restoration of liver size and function within weeks [4]. This enables to maintain a constant liver to body weight ratio, which is crucial for adult body homeostasis, a concept called hepatostat [11]. Being the most abundant cell type, the hepatocytes play a central role in

\section{Periportal cells}

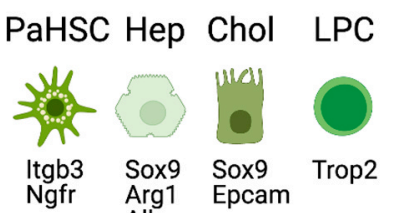

$\begin{array}{lll}\text { Itgb3 } & \text { Sox9 } & \text { Sox9 } \\ \text { Ngfr } & \text { Arg1 } & \text { Epcam } \\ & \text { Alb } & \end{array}$

Trop2

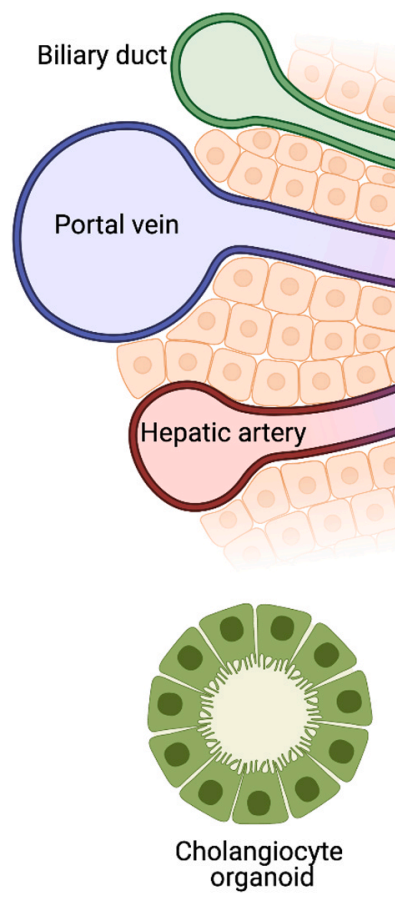

organoid
Midlobular zone

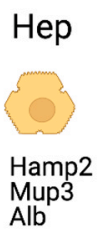

\section{Pericentral cells}

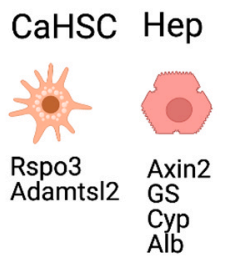
epithelial and mesenchymal compartment in vivo and in organoid cultures. The liver lobule is organised around the portal triad (formed by a biliary duct, hepatic artery and portal vein) and the central vein. In the portal side, cholangiocytes, Chol, form biliary ducts, and adult liver progenitor cells (LPC) arise in response to toxic injury. All hepatocytes, Hep, express Albumin (Alb). Periportal hepatocytes express the classic cholangiocyte marker Sox 9 and Arginase 1 (Arg1), a component of the urea cycle. Pericentral hepatocytes express Axin2, Glutamine synthetase (GS) and cytochromes (Суp), which are involved in drug metabolism. Midlobular hepatocytes have higher proliferation potential both in homeostasis and after tissue resection and toxic injury [31,32]. Mesenchymal HSCs can be classified into distinct subpopulations, named portal vein-associated HSCs (PaHSC) and central vein-associated HSCs (CaHSC) [70]. Adult human and mouse adult cholangiocyte organoids contribute to the repair of the damaged liver, recapitulate both the homeostatic and regenerative molecular profiles of cholangiocytes and have proven reliable human disease models [53,58,59,65]. Adult hepatocyte organoids recapitulate the regenerative hepatocyte state observed after partial hepatectomy and predominantly express pericentral markers in conditions promoting their expansion [33,34]. Human iPSC-derived multi-tissue liver organoids, which can include both epithelial cell types, hepatocytes and cholangiocytes, and stromal cells have been used as models of non-alcoholic steatohepatitis and drug-induced liver injury. They can contain both periportal and pericentral hepatocyte features [37-39]. 
the liver response to partial hepatectomy. Of note, after partial hepatectomy, the overall liver shape changes, thus indicating that the liver prioritises the replacement of its functional units over the restoration of its correct shape. The change in liver shape is due to a compensatory hypertrophy of the hepatocytes in the remnant liver, followed by a proliferation wave from the periportal to the pericentral area of the lobule [18]. This gradient of proliferation ensures restoration of the tissue mass while maintaining liver functionality, since proliferation is associated with reduced expression of functional hepatocyte genes [4]. Proliferation is also accompanied by the transient re-acquisition of chromatin and transcriptional profiles of foetal progenitors [19] and early postnatal hepatocytes [20]. This is consistent with the fact that adult hepatocytes can de-differentiate into bipotent liver progenitors after toxic damage [21-23], as they are capable to give rise to both hepatocytes and cholangiocytes, resembling the liver epithelial embryonic progenitors, the hepatoblasts $[2,3,24]$.

Although being slowly self-renewing in homeostasis, increasing evidence demonstrates that the majority of the hepatocytes can acquire proliferation in response to hepatectomy and toxic damage [25-27]. The nature of the injury determines the activation of the hepatocytes located in proximity to the injury source. Different regional markers defining hepatocytes subpopulations involved in homeostasis, damage-response and regeneration have been identified. Periportal hepatocytes express the classic cholangiocyte marker Sox9 [28]; pericentral hepatocytes express the WNT-related stem-cell marker Axin2 [29]; TERT $^{+}$hepatocytes are present throughout the liver parenchyma and in zonal boundaries [30]. Are all hepatocytes equally competent to proliferate and regenerate the liver? Recent findings highlight midlobular/zone 2 hepatocytes as the most proliferative hepatocyte population $[20,25,31$, 32]. Fate-mapping of 14 different hepatocyte populations in the mouse liver revealed that midlobular/zone 2 hepatocytes are the main proliferative hepatocyte population in homeostasis [31]. EdU labelling showed that midlobular/zone 2 hepatocytes exhibit higher proliferation potential in response to partial hepatectomy [20]. Midlobular/zone 2 hepatocytes also contribute to liver regeneration both after periportal injury induced by the 3,5-Diethoxycarbonyl-1,4-Dihydrocollidine (DDC) diet, which damages zone 1 hepatocytes, and pericentral injury induced by Carbon tetrachloride ( $\mathrm{CCl} 4$ ), which damages zone 3 hepatocytes [31]. A genetic strategy called ProTracer, which allows continuous recording of in vivo cell proliferation, confirmed that midlobular/zone 2 hepatocytes exhibit more proliferation in both the homeostatic and damaged liver [32]. Why should the liver favour the response of the hepatocytes in midlobular/zone 2 over zone 1 and zone 3 ? Being further away from both the central (zone 3 ) and the portal vein (zone 1), where liver damage occurs, zone 2 is less susceptible to damage. Thus, midlobular hepatocytes appear to be a reservoir of proliferating hepatocytes protected from liver damage $[31,32]$. In addition, the increased proliferation capacity of midlobular/zone 2 hepatocytes may be a way to preserve liver metabolic functions, which are exerted predominantly by hepatocytes in zone 1 and 3. Supporting this, i) single-cell RNA-sequencing showed that periportal/zone 1 and pericentral/zone 3 hepatocytes maintain their metabolic competence, while midlobular/zone 2 hepatocytes proliferate after partial hepatectomy [20]; ii) ATAC-sequencing combined with RNA-sequencing showed that, after partial hepatectomy, a subset of hepatocytes retain chromatin accessibility and expression of genes involved in metabolic functions [19]. Together, this suggests that the peculiar spatial organisation allows the liver to preserve its vital metabolic functions in response to both tissue resection and toxic damage. Notably, all the different experimental approaches that highlighted the important role of midlobular hepatocytes, revealed also high regional hepatocyte proliferation after damage. Therefore, this confirms that the majority of the hepatocytes can acquire proliferation and that the spatial location within the liver lobule determines the activation of specific hepatocyte subpopulations according to the type of injury. The next challenge will be to determine the role of regional metabolic inputs and hepatocyte competence in the regulation of the epigenetic and transcriptional mechanisms that promote liver regeneration after damage [8].

\subsection{Hepatocyte organisation and function in organoid systems modelling liver regeneration and disease}

Is hepatocyte spatial organisation and geometry recapitulated in 3D organoid systems? Hepatocyte organoids can be derived from mouse liver tissue [33,34], human primary hepatocytes and foetal liver cells isolated from human embryos of 11-20 weeks of gestation [33]. Adult hepatocyte organoids have the potential to engraft into the damaged mouse liver and exhibit structured bile canaliculi and functional hepatocyte features [33,34]. In culture conditions promoting organoid expansion, hepatocyte organoids resemble the transcriptional profiles of the regenerative hepatocytes observed after partial hepatectomy and exhibit increased expression of pericentral hepatocytes markers [33,34]. However, change in culture conditions can induce the expression of periportal hepatocyte markers [34] and trans-differentiation into cholangiocytes [33], indicating that hepatocyte organoids exhibit high plasticity. Hepatocytes derived upon differentiation of human induced-pluripotent stem cells (iPSCs) can be grown together with endothelial and mesenchymal cells to form 3D structures resembling the liver bud, which become vascularised after transplantation in mouse $[35,36]$. iPSC-based methods also allow concomitant growth and specification of different liver cell types. Human iPSC-derived epithelial organoids, which contain both hepatocytes and cholangiocytes, have been used as a model of hepatic steatosis [37]. Human iPSC-derived multi-tissue organoids contain multiple stromal and epithelial liver cell types, including hepatocytes and cholangiocytes, Kupffer cells and HSCs. They allow modelling steatosis, inflammation and fibrosis observed in non-alcoholic steatohepatitis [38], and drug-induced cholestatic injury and mitochondrial toxicity [39]. Interestingly, human multi-tissue organoids established directly from iPSC differentiation show increased expression of periportal hepatocyte makers [38], whereas organoids established from iPSC-derived foregut progenitors show a similar amount of periportal and pericentral hepatocytes [39].

Together, these findings highlight adult and iPSC-derived hepatic organoids as models of hepatocyte-mediated liver regeneration and human liver disease. These organoid systems recapitulate, at least in part, mature hepatocyte functional properties and the complexity of the bile canaliculi. The next important challenge will be the identification of the culture conditions allowing recapitulating in vitro the hepatocyte zonation in the liver lobule.

\subsection{Biliary architecture and cholangiocyte heterogeneity in liver regeneration}

Cholangiocytes modify and collect the bile produced by the hepatocytes into biliary ducts, which are one of the defining elements of the portal triad. Intrahepatic biliary ducts converge into the common bile duct, which then exports the bile to the duodenum for digestive purposes $[40,41]$. Biliary ducts can be classified into small ductules $(<15 \mu \mathrm{m})$ and large ducts according to their diameter [41]. Biliary ductules are formed by small cholangiocytes, which are cuboidal in shape and characterised by tight junctions between cells and microvilli facing the lumen. Large cholangiocytes mostly define interlobular and extrahepatic ducts, are columnar in shape and have a primary cilium [41]. Heterogeneity in size and shape influences cholangiocyte regenerative capacity: large cholangiocytes exhibit higher proliferation in response to certain types of injury (e.g. bile acids, surgical ligation of the common bile duct and CC14); small cholangiocytes exhibit higher plasticity, being capable of restoring both small and large biliary ducts after injury [42]. Lineage-tracing experiments in response to damage induced by thioacetamide (TAA) showed that proliferative cholangiocytes are mainly located in the peripheral ductules [43]. Of note, heterogeneity was observed even within the peripheral compartment, since not all ductules 
exhibited proliferation, and the proliferative ductules gave rise to both small and large clusters, which is indicative of different rounds of cell division [43]. Senescent cholangiocytes can induce paracrine senescence in the surrounding periportal hepatocytes via TGF- $\beta$ dependent mechanisms, and compromise liver regenerative capacity after both periportal damage induced by DDC and partial hepatectomy [44]. Underlying the relevance of this paracrine mechanism, periportal hepatocytes exhibit senescence in human liver biopsies from patients with primary sclerosing cholangitis and primary biliary cholangitis [44].

Toxic injury induces biliary proliferation and expansion of biliary ducts in both mouse and human liver, a phenomenon called ductular reaction [45]. These expanding ductal branches are associated with the establishment of bipotent liver progenitors capable of regenerating the epithelial compartment after damage $[6,8,46]$. Both adult liver epithelial cell types can de-differentiate into bipotent liver progenitors, consistent with the developmental origin of both hepatocytes and intrahepatic cholangiocytes from a common embryonic progenitor, the hepatoblast $[2,3,24]$. These adult bipotent liver progenitors originate predominantly in a specific location of the liver lobule, the canal of Hering, which is the finest ramification of the biliary tree, connecting the bile canaliculi and large intrahepatic and extrahepatic biliary ducts [47]. Therefore, this suggests that the canal of Hering provides a favourable environment to acquire a bipotent progenitor state. Whether this is due to specific signalling molecules and cytokines or to enriched hepatocyte-cholangiocyte cell interactions in this area of the liver lobule, remains unknown. Adult liver progenitors acquire a specific molecular signature, including the expression of TROP2 [48,107], and can infiltrate the parenchyma to repair the epithelial architecture [46]. How adult liver progenitors sense the damage, and how their migration patterns within the parenchyma influence liver regeneration, is unclear. This progenitor response to injury is crucial for liver regeneration when the hepatocytes are compromised (e.g. chronic injury, over-expression of $\mathrm{p} 21$, deletion of Mdm2, $\beta 1$ integrin or $\beta$-catenin) [49-52,108]. In this scenario, lineage-tracing experiments in mouse models demonstrated that intrahepatic cholangiocytes act as facultative liver progenitors, which restore up to $70 \%$ of total hepatocytes [49-52]. Are all cholangiocytes capable to acquire a bipotent progenitor state? Our data indicated that $\sim 15 \%$ of adult mature cholangiocytes isolated from the mouse healthy liver can acquire a bipotent progenitor state when grown as organoid cultures [53]. Supporting a degree of heterogeneity within cholangiocytes, $\sim 25 \%$ of cholangiocytes show high activity of the YAP/TAZ signalling in the liver [54], which is required for cholangioyte regenerative properties $[54,55]$. However, increased YAP/TAZ levels do not appear to be an intrinsic feature of a distinct cholangiocyte progenitor-like subpopulation in the homeostatic liver; on the contrary, YAP/TAZ levels become dynamically up-regulated in response to bile acid-induced injury [54], consistent with the function of the cholangiocytes to collect and modify the bile. Supporting a dynamic regulation of the cholangiocyte progenitor state, we found that transient epigenetic remodelling, occuring at early stages after liver damage in vivo, sustains the activity of the YAP/TAZ signalling and is required for the expression of stem-cell genes to drive the de-differentiation of mature cholangiocytes into bipotent liver progenitors [53].

Together, these findings indicate that cholangiocytes exhibit high plasticity in response to injury, which is required to regenerate the biliary tree and restore the damaged liver epithelia when the hepatocytes are compromised. Further characterisation of the mechanisms regulating cholangiocyte heterogeneity and plasticity will have important implications for regenerative medicine to repair the vast hepatocyte necrosis and senescence detected in chronic liver disease [56] and for treatment of liver cancer, where prominent progenitor features are associated with a poor prognosis [57].

\subsection{Cholangiocyte organoids as models of cholangiocyte-mediated regeneration and human liver disease}

Cholangiocyte organoids can be derived from human and mouse adult liver tissue biopsies. They can be derived from intrahepatic [58, 59] and extrahepatic [60,61] biliary ducts, and the gallbladder [62] or from iPSCs $[63,64]$. Adult cholangiocyte organoids are self-renewing cultures, named intrahepatic (ICOs), extrahepatic (ECOs) and gallbladder (GCOs) cholangiocyte organoids according to the cell of origin [10]. ICOs express stem-cell genes defining bipotent adult liver progenitors in vivo (e.g. Trop2) $[53,58,59]$ and recapitulate the transcriptional and epigenetic profiles of regenerative cholangiocytes in the mouse injured liver in vivo [53]. Consistent with their resemblance of bipotent liver progenitors, ICOs can differentiate into functional hepatocytes in vitro and upon transplantation in vivo, showing engraftment potential in the damaged mouse liver, although with low efficiency [58, 59]. Confirming their high plasticity, adult cholangiocyte organoids derived from one region of the biliary tree can repair different regions of the biliary tree after transplantation in vivo [65]. Remarkably, upon transplantation into the intrahepatic biliary tree of human donor livers showing ischaemic duct injury, human GCOs were shown to regenerate $40 \%$ to $85 \%$ of the injected human biliary ducts [65]. Of note, GCOs did not form hepatocytes upon transplantation in human donor livers [65], thus suggesting that either these experimental conditions specifically promoted the restoration of the damaged biliary tree or that differentiation into hepatocytes is a unique property of intrahepatic cholangiocytes. The latter is in line with the common developmental origin of intrahepatic cholangiocytes and hepatocytes from the hepatoblasts, whereas extrahepatic cholangiocytes have a common developmental origin with the pancreas and duodenum $[2,3,24]$.

Together, these findings show that cholangiocyte organoids retain the cholangiocyte plasticity observed during liver regeneration, and are promising systems for regenerative medicine, taking advantage of their long-term expansion in vitro and their capacity of engraftment in the damaged liver in vivo.

\section{The mesenchymal compartment and ECM deposition in liver regeneration and disease}

Resident liver mesenchymal cells can stimulate the response to injury mediated by liver progenitors, via secretion of growth factors $[4,7]$. For example, after periportal damage induced by DDC, mesenchymal Fgf7 promotes the activation of liver progenitors $[66,67]$ and secretion of the Notch-ligand Jagged 1 promotes differentiation of the progenitors to restore biliary ducts [68]. In addition, mesenchymal cells regulate the proliferation capacity of adult liver progenitors via direct cell contacts in vivo after liver injury induced by DDC [69]. Single-cell transcriptomics have identified three distinct adult liver mesenchymal populations, which all express the mesenchymal marker PDGFR $\beta$ : i) Calponin $1+$ cells, located within the vein walls; ii) CD34+ cells, located in proximity of the biliary ducts; iii) Reelin + cells, located throughout the liver parenchyma, in the space of Disse, the space between sinusoids and hepatocytes [70]. Reelin + cells are associated with the classic gene signature that define the hepatic stellate cells (HSCs) [70]. In the healthy liver, HSCs are responsible for lipid and retinoic acid storage and maintain a quiescent phenotype. After liver injury, HSCs become activated into myofibroblasts, which secrete collagen, inducing ECM remodelling to repair the damaged tissue $[71,72]$. HSCs can be further distinguished into 2 distinct subpopulations according to their spatial location within the liver lobule. Namely, the expression of Ngfr and Itgb3 is associated with HSCs located in the proximity of the portal vein, whereas Adamtsl2 and Rspo3 expression defines HSCs located in the proximity of the central vein [70] (Fig. 1). Notably, single-cell transcriptomic analyses in the cirrhotic liver identified heterogeneity in mesenchymal cells based on their periportal or pericentral spatial location [73], similar to what observed in mouse [70]. Intriguingly, 
some of the regional HSC markers also define distinct endothelial cell populations according to their pericentral and periportal location [74, 75]. For instance, pericentral sinusoidal endothelial cells are also a major source of RSPO proteins and secrete WNT ligands, which activate the WNT signalling pathway $[20,29,74,75]$. Therefore, this suggests that local cues favour the expression of a common molecular signature in the stromal compartment, which in turn, stimulates the regenerative capacity of epithelial subpopulations located in their proximity. Confirming the importance of the spatial location in the regulation of the response to injury, central-vein associated HSCs predominantly respond to pericentral injury induced by CCl4 [70].

HSC hyperactivation in response to damage leads to aberrant secretion and accumulation of ECM. Thus, HSCs represent the main contributors to liver fibrosis [76], which can degenerate into cirrhosis and predispose to liver cancer [9]. ECM changes are determined by the balance of ECM secretion and degradation. ECM degradation is due to the activity of metalloproteinases, which can have important anti-fibrotic effects [77]. Supporting the activation of distinct mesenchymal subpopulations after liver injury, fibrosis can be prevalently located in different areas of the lobule. Fibrosis is a double-edged sword with both pro-regenerative and detrimental effects in the liver [78]. On the one hand, fibrosis impairs the exchange of nutrient and metabolism between the hepatocytes and the blood in the space of Disse, leading to liver dysfunction. On the other hand, fibrosis appears to play an important role in the spatial isolation of clonal nodules that exhibit malignant mutations in the cirrhotic liver, exerting a protective effect towards the insurgence of liver cancer $[79,80]$. Moreover, the damaged fibrotic environment triggers the regenerative response and repair of the damaged epithelia mediated by liver progenitors in mouse models of liver injury [49-52] and human liver disease [81-83]. However, in vitro exposure to chemically defined hydrogels that resemble the stiffness of the diseased liver, reduces progenitor proliferation and expression of stem-cell genes [84]. Increasing evidence indicates that regulation of fibrosis is highly dependent on the local microenvironment. Senescent cholangiocytes, cholangiocyte-mediated non-canonical WNT signalling, and damaged hepatocytes determine recruitment of macrophages and myofibroblasts, leading to increased collagen deposition in the damaged liver $[44,85,86]$.

These findings highlight a key role for the spatial organisation and geometry of the mesenchymal compartment and the fibrotic microenvironment in liver regeneration and disease. Further investigation of the regional interplay between epithelial and mesenchymal cells will elucidate how local concentrations of growth factors and ECM mediate the balance between liver regeneration and disease.

\section{The YAP/TAZ signalling in liver regeneration and disease}

How do ECM remodelling and increased stiffness in the damaged liver influence the epithelial cells at the molecular level? Increased tissue stiffness induces nuclear translocation of the transcriptional coactivators YAP and TAZ, which are key mediators of mechanotransduction [87]. The interplay between ECM and YAP/TAZ is bidirectional, since YAP expression is induced in both HSCs [88] and hepatocytes [86] after liver injury, promoting collagen deposition and liver fibrosis. Additional inputs affect the YAP/TAZ signalling: i) their nuclear translocation is regulated by intermediate metabolites of the mevalonate pathway [89]; ii) their expression is regulated by the Hippo pathway via phosphorylation mediated by Lats1/2, which leads to YAP/TAZ degradation [90]. YAP/TAZ nuclear translocation leads to binding to the TEAD transcription factors and transcriptional activation of key genes for liver growth and regeneration, including the connective tissue growth factor Ctgf and components of the Notch signalling pathway [90].

The YAP/TAZ signalling pathway is a key determinant of liver size; over-expression of YAP is sufficient to determine an increase in liver size of $>4$ fold $[91,92]$. Remarkably, YAP activation is an early event in liver cancer development [93] and YAP over-expression is sufficient to induce liver cancer [92]. YAP is required for the maintenance of the homeostatic biliary ducts [54] and is a sensor of bile canaliculi remodelling induced by partial hepatectomy, which induces YAP recruitment to the hepatocyte apical cortex and subsequent YAP nuclear translocation and activation [94]. Importantly, YAP/TAZ are required for liver regeneration mediated by both hepatocytes and cholangiocytes in vivo [23,54, 55], determining their de-differentiation into bipotent liver progenitors $[23,53]$. The expression and activity of YAP/TAZ are regulated by epigenetic mechanisms dependent on ARID1A in hepatocytes [95] and TET1 in cholangiocytes [53]. Of note, TET1-mediated epigenetic remodelling occurs transiently at early stages after liver injury [53], suggesting that TET1-dependent epigenetic mechanisms tightly control YAP/TAZ activity in the injured liver to avoid the detrimental effects of YAP/TAZ hyperactivation, including liver cancer. The activation of YAP/TAZ in response to liver injury occurs predominantly in the portal triad of the liver lobule, in both cholangiocytes [53-55] and periportal hepatocytes $[23,86]$. Periportal hepatocytes show higher expression of genes involved in lipid and cholesterol biosynthesis [74], which have been involved in YAP/TAZ nuclear translocation [89]. Therefore, this suggests that the metabolic competence of the periportal hepatocytes may favour their de-differentiation and formation of liver progenitors. In addition, 2-oxoglutarate (2-OG) synthesis by the hepatocytes has been shown to contribute to the maintenance of the undifferentiated state of liver progenitors [96]. Of note, TET1 epigenetic activity inducing cholangiocyte de-differentiation, is dependent on 2-OG [97]. Thus, an intriguing hypothesis is that the hepatocyte metabolic activity contributes to TET1-dependent YAP/TAZ activation and in turn, to cholangiocyte de-differentiation into bipotent liver progenitors in the periportal area of the lobule [53] (Fig. 2). YAP activity also enhances glutamine synthetase expression [98] and can be activated by hypoxia [99] and glycolysis [100], thus suggesting that YAP/TAZ may also play an important role also in regeneration of the pericentral area of the lobule, which shows higher glycolytic and glutamine synthesis activity, and lower oxygen levels.

Together, this indicates that epigenetic, metabolic and ECM remodelling in response to injury determines the activation of the YAP/ TAZ signalling in the liver. The dynamic regulation and high responsiveness to different stimuli, further suggest that YAP/TAZ act as a central hub that regulates liver progenitor activation and regenerative capacity (Fig. 2). Thus, a better understanding of the mechanisms that regulate YAP/TAZ activity, will shed light on how different inputs mediates the balance between pro-regenerative and disease-associated YAP/TAZ activity in the damaged liver.

\section{Conclusions}

Liver tissue geometry and functional organisation is determined by the direction of the blood flow, from the portal triad to the central vein, generating a gradient of oxygen and nutrients within the liver lobule. The recent development of single-cell transcriptomics, combined with lineage-tracing in mouse models, have allowed the identification of subpopulations of epithelial and mesenchymal cells that show distinct molecular signatures according to their spatial location in the liver lobule (Fig. 1). In this review, I have summarised the latest evidence showing an important role for tissue spatial geometry in the regenerative response and functions of these subpopulations. Together, these findings indicate that the liver regenerative response is dependent on the type of injury and relies on local liver compartments, which become differentially activated according to the proximity to the site of injury. However, the regenerative capacity of different epithelial and mesenchymal subpopulations relies, at least in part, on the activation of a common set of molecular mechanisms. For instance, the activation of the YAP/TAZ signalling occurs in both periportal hepatocytes and cholangiocytes [23,53-55] (Fig. 2). In addition, epigenetic remodelling of the DNA methylome and hydroxymethylome occurs in both 


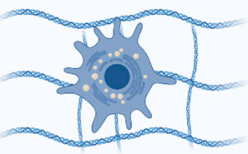

\section{Homeostasis}

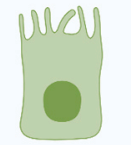

Injury/Regeneration

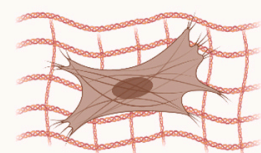

ECM remodelling
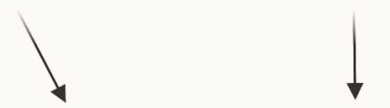

Cholangiocyte

Periportal hepatocyte

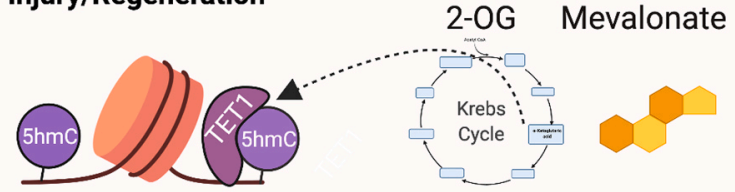

Epigenetic remodelling

Metabolic remodelling

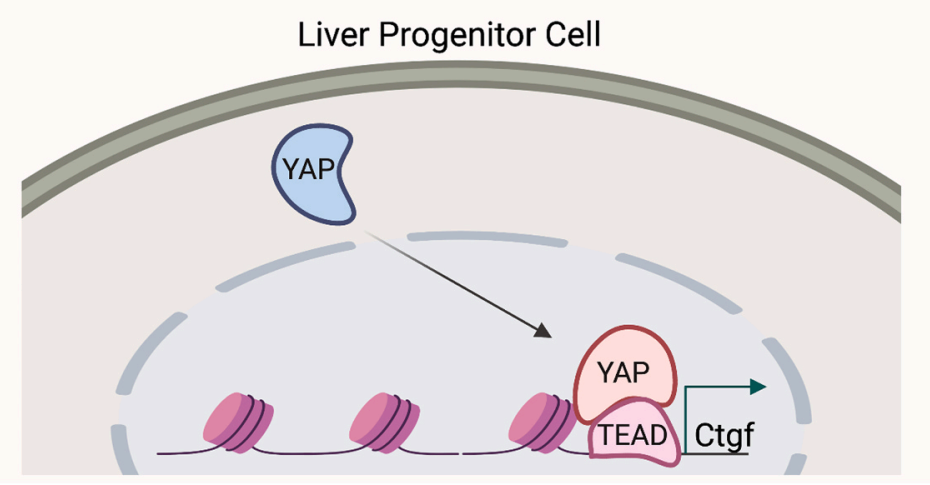

Fig. 2. YAP/TAZ signalling in liver regeneration. YAP/ TAZ signalling is required for liver regeneration mediated by adult liver progenitors, promoting de-differentiation of hepatocytes and cholangiocytes into bipotent liver progenitors [23,53-55]. YAP/TAZ are transcriptional co-activators that promote the expression of target genes (e.g. Ctgf) in association with TEAD transcription factors. YAP/TAZ act as a central hub that promotes regeneration mediated by adult liver progenitors in the damaged liver, by sensing remodelling of 1) extra-cellular matrix (ECM), 2) epigenetic landscape and 3) metabolic profiles. 1) Left: hepatic stellate cells become activated in response to injury and secrete collagen. Increased ECM stiffness due to collagen secretion promotes YAP/TAZ nuclear translocation. 2) Middle: epigenetic remodelling mediated by the methylcytosine dioxygenase TET1 and its epigenetic mark DNA 5-hydroxymethylcytosine $(5 \mathrm{hmC})$, drives cholangiocyte de-differentiation into regenerative bipotent progenitors, via regulation of members and targets of the YAP/TAZ-mediated signalling [53]. 3) Right: metabolic inputs from the hepatocytes, such as increased levels of 2-oxoglutarate (2-OG), may favour the maintenance of the undifferentiated state of liver progenitors after injury [96]. Being a co-factor of TET enzymes, 2-OG might sustain TET1-depedent YAP/TAZ expression and transcriptional activity in liver progenitors. Intermediates of the mevalonate pathway in periportal hepatocytes [89], could facilitate YAP/TAZ nuclear translocation and de-differentiation of hepatocytes into bipotent liver progenitors. cholangiocytes [53] and HSCs [101] in response to liver injury. Whether the same transient epigenetic remodelling that promotes cholangiocyte de-differentiation into bipotent liver progenitors [53] also drives the expression of embryonic and postnatal markers in hepatocytes in response to tissue resection and damage $[19,20,23]$, remains to be determined. Epigenetic mechanisms are crucial regulators of the cell-fate decisions that determine efficient liver regeneration after damage [8] and are implicated in liver disease and cancer [102]. Further work is needed to associate transcriptomic profiles and metabolic competence of adult liver epithelial and mesenchymal subpopulations with their epigenetic profiles. Such integrated analyses would lead to the identification of the regulatory networks underlying the plasticity and regenerative capacity of the different liver compartments and their implications in liver disease and cancer.

The establishment of 3D hepatic organoid systems has recently allowed modelling key aspects of liver regeneration, disease and cancer in a dish [10]. iPSC-derived organoids allow concomitant specification of multiple liver epithelial and stromal cell types [37-39]; however further characterisation at the transcriptional and epigenetic level is needed to determine how much of the embryonic signature is retained in these cultures. Adult organoid systems recapitulate the transcriptional and epigenetic profiles of homeostatic, regenerative and cancerous adult liver epithelial cells in vivo $[33,34,53,58,59,65,103]$. However, the potential of adult organoids to mimic the liver microenvironment remains to date limited since they solely contain epithelial cells. Importantly, the use of Matrigel (an ECM mixture derived from mouse sarcoma) as the main ECM embedding the organoids, does not allow recapitulating the stiffness and the composition of the ECM observed in the regenerative and diseased liver in vivo. The recent development of chemically defined hydrogels showing different levels of stiffness offers the opportunity to grow liver progenitors in conditions more closely resembling the ECM changes observed in response to injury in vivo [84,104]. Moreover, these chemically-defined hydrogels open new horizons for transplantation of liver organoids in patients with liver disease, which has been shown as a promising option for regenerative medicine [65]. New approaches are indeed needed to tackle human chronic liver disease, which causes 2 million deaths per year worldwide [9], since liver transplantation remains the only effective therapeutic option, but it is limited to donor availability.

Given their key role in liver regeneration and disease, a better understanding of the mechanisms underlying the physical and functional local cellular interactions within the liver lobule, will represent a key step to design targeted approaches to stimulate liver regeneration via the activation of specific niche compartments. For instance, macrophages hold great promise for regenerative medicine to treat liver disease [105]. The role of inflammation in liver regeneration and the potential clinical applications have been elegantly reviewed elsewhere [106]. The next important challenge is represented by the identification of mesenchymal subpopulations that can be employed in regenerative medicine to stimulate the regenerative potential of epithelial cells and improve the outcome of chronic liver disease.

\section{Declaration of Competing Interest}

The authors declare that they have no known competing financial interests or personal relationships that could have appeared to influence the work reported in this paper.

\section{Acknowledgments}

This work was supported by MRC core funding to the MRC Laboratory for Molecular Cell Biology at University College London, award code (MC_U12266B). LA thanks the members of the laboratory for helpful discussions. LA apologises to all the authors whose work could 
not be cited due to space limitations. The graphical abstract and the figures were created with Biorender.com.

\section{References}

[1] E. Trefts, M. Gannon, D.H. Wasserman, The liver, Curr. Biol. 27 (21) (2017) R1147-R1151, https://doi.org/10.1016/j.cub.2017.09.019.

[2] M. Gordillo, T. Evans, V. Gouon-Evans, Orchestrating liver development, Development 142 (12) (2015) 2094-2108, https://doi.org/10.1242/dev.114215.

[3] E.A. Ober, F.P. Lemaigre, Development of the liver: insights into organ and tissue morphogenesis, J. Hepatol. 68 (5) (2018) 1049-1062, https://doi.org/10.1016/j. jhep.2018.01.005.

[4] G.K. Michalopoulos, Liver regeneration, J. Cell Physiol. 213 (2) (2007) 286-300, https://doi.org/10.1002/jcp.21172.

[5] L. Aloia, M.A. McKie, M. Huch, Cellular plasticity in the adult liver and stomach, J. Physiol. 594 (17) (2016) 4815-4825, https://doi.org/10.1113/JP271769.

[6] V.L. Gadd, N. Aleksieva, S.J. Forbes, Epithelial plasticity during liver injury and regeneration, Cell Stem Cell 27 (4) (2020) 557-573, https://doi.org/10.1016/j. stem.2020.08.016.

[7] L.J. Kitto, N.C. Henderson, Hepatic stellate cell regulation of liver regeneration and repair, Hepatol. Commun. 5 (3) (2021) 358-370, https://doi.org/10.1002/ hep4.1628.

[8] L. Aloia, Epigenetic regulation of cell-fate changes that determine adult liver regeneration after injury, Front Cell Dev. Biol. 9 (2021), 643055, https://doi.org/ 10.3389/fcell.2021.643055.

[9] S.K. Asrani, H. Devarbhavi, J. Eaton, P.S. Kamath, Burden of liver diseases in the world, J. Hepatol. 70 (1) (2019) 151-171, https://doi.org/10.1016/j. jhep.2018.09.014.

[10] A. Marsee, F. Roos, M. Verstegen, C. HPB Organoid, H. Gehart, E. de Koning, F. Lemaigre, S.J. Forbes, W.C. Peng, M. Huch, T. Takebe, L. Vallier, H. Clevers, L. van der Laan, B. Spee, Building consensus on definition and nomenclature of hepatic, pancreatic, and biliary organoids, Cell Stem Cell 28 (5) (2021) 816-832, https://doi.org/10.1016/j.stem.2021.04.005.

[11] G.K. Michalopoulos, Hepatostat: Liver regeneration and normal liver tissue maintenance, Hepatology 65 (4) (2017) 1384-1392, https://doi.org/10.1002/ hep.28988.

[12] J.R. Schaub, Y. Malato, C. Gormond, H. Willenbring, Evidence against a stem cell origin of new hepatocytes in a common mouse model of chronic liver injury, Cell Rep. 8 (4) (2014) 933-939, https://doi.org/10.1016/j.celrep.2014.07.003.

[13] K. Yanger, D. Knigin, Y. Zong, L. Maggs, G. Gu, H. Akiyama, E. Pikarsky, B. Z. Stanger, Adult hepatocytes are generated by self-duplication rather than stem cell differentiation, Cell Stem Cell 15 (3) (2014) 340-349, https://doi.org/ 10.1016/j.stem.2014.06.003.

[14] A. Treyer, A. Musch, Hepatocyte polarity, Compr. Physiol. 3 (1) (2013) 243-287, https://doi.org/10.1002/cphy.c120009.

[15] P. Gissen, I.M. Arias, Structural and functional hepatocyte polarity and liver disease, J. Hepatol. 63 (4) (2015) 1023-1037, https://doi.org/10.1016/j. jhep. 2015.06.015.

[16] S. Hoehme, M. Brulport, A. Bauer, E. Bedawy, W. Schormann, M. Hermes, V. Puppe, R. Gebhardt, S. Zellmer, M. Schwarz, E. Bockamp, T. Timmel, J. G. Hengstler, D. Drasdo, Prediction and validation of cell alignment along microvessels as order principle to restore tissue architecture in liver regeneration, Proc. Natl. Acad. Sci. USA 107 (23) (2010) 10371-10376, https://doi.org/ 10.1073/pnas.0909374107.

[17] J. Ishikawa, M. Takeo, A. Iwadate, J. Koya, M. Kihira, M. Oshima, Y. Suzuki, K. Taniguchi, A. Kobayashi, T. Tsuji, Mechanical homeostasis of liver sinusoid is involved in the initiation and termination of liver regeneration, Commun. Biol. 4 (1) (2021) 409, https://doi.org/10.1038/s42003-021-01936-2.

[18] Y. Miyaoka, K. Ebato, H. Kato, S. Arakawa, S. Shimizu, A. Miyajima, Hypertrophy and unconventional cell division of hepatocytes underlie liver regeneration, Curr. Biol. 22 (13) (2012) 1166-1175, https://doi.org/10.1016/j.cub.2012.05.016.

[19] T. Chen, S. Oh, S. Gregory, X. Shen, A.M. Diehl, Single-cell omics analysis reveal functional diversification of hepatocytes during liver regeneration, JCI Insight 5 (22) (2020), https://doi.org/10.1172/jci.insight.141024.

[20] U.V. Chembazhi, S. Bangru, M. Hernaez, A. Kalsotra, Cellular plasticity balances the metabolic and proliferation dynamics of a regenerating liver, Genome Res. 31 (4) (2021) 576-591, https://doi.org/10.1101/gr.267013.120.

[21] X. Han, Y. Wang, W. Pu, X. Huang, L. Qiu, Y. Li, W. Yu, H. Zhao, X. Liu, L. He, L. Zhang, Y. Ji, J. Lu, K.O. Lui, B. Zhou, Lineage tracing reveals the bipotency of SOX9(+) hepatocytes during liver regeneration, Stem Cell Rep. 12 (3) (2019) 624-638, https://doi.org/10.1016/j.stemcr.2019.01.010.

[22] B.D. Tarlow, C. Pelz, W.E. Naugler, L. Wakefield, E.M. Wilson, M.J. Finegold, M. Grompe, Bipotential adult liver progenitors are derived from chronically injured mature hepatocytes, Cell Stem Cell 15 (5) (2014) 605-618, https://doi. org/10.1016/j.stem.2014.09.008.

[23] D. Yimlamai, C. Christodoulou, G.G. Galli, K. Yanger, B. Pepe-Mooney, B. Gurung, K. Shrestha, P. Cahan, B.Z. Stanger, F.D. Camargo, Hippo pathway activity influences liver cell fate, Cell 157 (6) (2014) 1324-1338, https://doi.org/ 10.1016/j.cell.2014.03.060.

[24] K.S. Zaret, M. Grompe, Generation and regeneration of cells of the liver and pancreas, Science 322 (5907) (2008) 1490-1494, https://doi.org/10.1126/ science. 1161431.

[25] F. Chen, R.J. Jimenez, K. Sharma, H.Y. Luu, B.Y. Hsu, A. Ravindranathan, B. A. Stohr, $\mathrm{H}$. Willenbring, Broad distribution of hepatocyte proliferation in liver homeostasis and regeneration, e4, Cell Stem Cell 26 (1) (2020) 27-33, https:// doi.org/10.1016/j.stem.2019.11.001.

[26] T. Matsumoto, L. Wakefield, B.D. Tarlow, M. Grompe, In vivo lineage tracing of polyploid hepatocytes reveals extensive proliferation during liver regeneration, e3, Cell Stem Cell 26 (1) (2020) 34-47, https://doi.org/10.1016/j. stem.2019.11.014.

[27] T. Sun, M. Pikiolek, V. Orsini, S. Bergling, S. Holwerda, L. Morelli, P.S. Hoppe, L. Planas-Paz, Y. Yang, H. Ruffner, T. Bouwmeester, F. Lohmann, L. M. Terracciano, G. Roma, F. Cong, J.S. Tchorz, AXIN2(+) pericentral hepatocytes have limited contributions to liver homeostasis and regeneration, e6, Cell Stem Cell 26 (1) (2020) 97-107, https://doi.org/10.1016/j.stem.2019.10.011.

[28] J. Font-Burgada, S. Shalapour, S. Ramaswamy, B. Hsueh, D. Rossell, A. Umemura, K. Taniguchi, H. Nakagawa, M.A. Valasek, L. Ye, J.L. Kopp, M. Sander, H. Carter, K. Deisseroth, I.M. Verma, M. Karin, Hybrid periportal hepatocytes regenerate the injured liver without giving rise to cancer, Cell 162 (4) (2015) 766-779, https:// doi.org/10.1016/j.cell.2015.07.026.

[29] B. Wang, L. Zhao, M. Fish, C.Y. Logan, R. Nusse, Self-renewing diploid Axin2(+) cells fuel homeostatic renewal of the liver, Nature 524 (7564) (2015) 180-185, https://doi.org/10.1038/nature14863.

[30] S. Lin, E.M. Nascimento, C.R. Gajera, L. Chen, P. Neuhöfer, A. Garbuzov, S. Wang, S.E. Artandi, Distributed hepatocytes expressing telomerase repopulate the liver in homeostasis and injury, Nature 556 (7700) (2018) 244-248, https://doi.org/ 10.1038/s41586-018-0004-7.

[31] Y. Wei, Y.G. Wang, Y. Jia, L. Li, J. Yoon, S. Zhang, Z. Wang, Y. Zhang, M. Zhu, T. Sharma, Y.H. Lin, M.H. Hsieh, J.H. Albrecht, P.T. Le, C.J. Rosen, T. Wang, $\mathrm{H}$. Zhu, Liver homeostasis is maintained by midlobular zone 2 hepatocytes, Science 371 (6532) (2021), https://doi.org/10.1126/science.abb1625.

[32] L. He, W. Pu, X. Liu, Z. Zhang, M. Han, Y. Li, X. Huang, X. Han, Y. Li, K. Liu, M. Shi, L. Lai, R. Sun, Q.D. Wang, Y. Ji, J.S. Tchorz, B. Zhou, Proliferation tracing reveals regional hepatocyte generation in liver homeostasis and repair, Science 371 (6532) (2021), https://doi.org/10.1126/science.abc4346.

[33] H. Hu, H. Gehart, B. Artegiani, C. LÖpez-Iglesias, F. Dekkers, O. Basak, J. van Es, S.M. Chuva de Sousa Lopes, H. Begthel, J. Korving, M. van den Born, C. Zou, C. Quirk, L. Chiriboga, C.M. Rice, S. Ma, A. Rios, P.J. Peters, Y.P. de Jong, H. Clevers, Long-term expansion of functional mouse and human hepatocytes as 3D organoids, e19, Cell 175 (6) (2018) 1591-1606, https://doi.org/10.1016/j. cell.2018.11.013.

[34] W.C. Peng, C.Y. Logan, M. Fish, T. Anbarchian, F. Aguisanda, A. Álvarez-Varela, P. Wu, Y. Jin, J. Zhu, B. Li, M. Grompe, B. Wang, R. Nusse, Inflammatory cytokine TNFalpha promotes the long-term expansion of primary hepatocytes in 3D culture, e15, Cell 175 (6) (2018) 1607-1619, https://doi.org/10.1016/j. cell.2018.11.012.

[35] T. Takebe, K. Sekine, M. Enomura, H. Koike, M. Kimura, T. Ogaeri, R.R. Zhang, Y. Ueno, Y.W. Zheng, N. Koike, S. Aoyama, Y. Adachi, H. Taniguchi, Vascularized and functional human liver from an iPSC-derived organ bud transplant, Nature 499 (7459) (2013) 481-484, https://doi.org/10.1038/nature12271.

[36] T. Takebe, K. Sekine, M. Kimura, E. Yoshizawa, S. Ayano, M. Koido, S. Funayama, N. Nakanishi, T. Hisai, T. Kobayashi, T. Kasai, R. Kitada, A. Mori, H. Ayabe, Y. Ejiri, N. Amimoto, Y. Yamazaki, S. Ogawa, M. Ishikawa, Y. Kiyota, Y. Sato, K. Nozawa, S. Okamoto, Y. Ueno, H. Taniguchi, Massive and reproducible production of liver buds entirely from human pluripotent stem cells, Cell Rep. 21 (10) (2017) 2661-2670, https://doi.org/10.1016/j.celrep.2017.11.005.

[37] M.N.B. Ramli, Y.S. Lim, C.T. Koe, D. Demircioglu, W. Tng, K. Gonzales, C.P. Tan, I. Szczerbinska, H. Liang, E.L. Soe, Z. Lu, C. Ariyachet, K.M. Yu, S.H. Koh, L. P. Yaw, N. Jumat, J. Lim, G. Wright, A. Shabbir, Y.Y. Dan, H.H. Ng, Y.S. Chan, Human pluripotent stem cell-derived organoids as models of liver disease, e12, Gastroenterology 159 (4) (2020) 1471-1486, https://doi.org/10.1053/j. gastro.2020.06.010.

[38] R. Ouchi, S. Togo, M. Kimura, T. Shinozawa, M. Koido, H. Koike, W. Thompson, R.A. Karns, C.N. Mayhew, P.S. McGrath, H.A. McCauley, R.R. Zhang, K. Lewis, S. Hakozaki, A. Ferguson, N. Saiki, Y. Yoneyama, I. Takeuchi, Y. Mabuchi, C. Akazawa, H.Y. Yoshikawa, J.M. Wells, T. Takebe, Modeling steatohepatitis in humans with pluripotent stem cell-derived organoids, e6, Cell Metab. 30 (2) (2019) 374-384, https://doi.org/10.1016/j.cmet.2019.05.007.

[39] T. Shinozawa, M. Kimura, Y. Cai, N. Saiki, Y. Yoneyama, R. Ouchi, H. Koike M. Maezawa, R.R. Zhang, A. Dunn, A. Ferguson, S. Togo, K. Lewis, W. L. Thompson, A. Asai, T. Takebe, High-fidelity drug-induced liver injury screen using human pluripotent stem cell-derived organoids, e10, Gastroenterology 160 (3) (2021) 831-846, https://doi.org/10.1053/j.gastro.2020.10.002.

[40] J.H. Tabibian, A.I. Masyuk, T.V. Masyuk, S.P. O'Hara, N.F. LaRusso, Physiology of cholangiocytes, Compr. Physiol. 3 (1) (2013) 541-565, https://doi.org/ 10.1002/cphy.c120019.

[41] Y. Han, S. Glaser, F. Meng, H. Francis, M. Marzioni, K. McDaniel, D. Alvaro, J. Venter, G. Carpino, P. Onori, E. Gaudio, G. Alpini, A. Franchitto, Recent advances in the morphological and functional heterogeneity of the biliary epithelium, Exp. Biol. Med. 238 (5) (2013) 549-565, https://doi.org/10.1177/ 1535370213489926.

[42] C. Hall, K. Sato, N. Wu, T. Zhou, K. Kyritsi, F. Meng, S. Glaser, G. Alpini, Regulators of cholangiocyte proliferation, Gene Expr. 17 (2) (2017) 155-171, https://doi.org/10.3727/105221616X692568.

[43] K. Kamimoto, K. Kaneko, C.Y. Kok, H. Okada, A. Miyajima, T. Itoh, Heterogeneity and stochastic growth regulation of biliary epithelial cells dictate dynamic epithelial tissue remodeling, Elife 5 (2016) 5, https://doi.org/10.7554/ eLife.15034.

[44] S. Ferreira-Gonzalez, W.Y. Lu, A. Raven, B. Dwyer, T.Y. Man, E. O’Duibhir, P. Lewis, L. Campana, T.J. Kendall, T.G. Bird, N. Tarrats, J.C. Acosta, L. Boulter, S. 
J. Forbes, Paracrine cellular senescence exacerbates biliary injury and impairs regeneration, Nat. Commun. 9 (1) (2018) 1020, https://doi.org/10.1038/ s41467-018-03299-5.

[45] T.A. Roskams, N.D. Theise, C. Balabaud, G. Bhagat, P.S. Bhathal, P. Bioulac-Sage, E.M. Brunt, J.M. Crawford, H.A. Crosby, V. Desmet, M.J. Finegold, S.A. Geller, A. S. Gouw, P. Hytiroglou, A.S. Knisely, M. Kojiro, J.H. Lefkowitch, Y. Nakanuma, J. K. Olynyk, Y.N. Park, B. Portmann, R. Saxena, P.J. Scheuer, A.J. Strain, S. N. Thung, I.R. Wanless, A.B. West, Nomenclature of the finer branches of the biliary tree: canals, ductules, and ductular reactions in human livers, Hepatology 39 (6) (2004) 1739-1745, https://doi.org/10.1002/hep.20130.

[46] T. Itoh, A. Miyajima, Liver regeneration by stem/progenitor cells, Hepatology 59 (4) (2014) 1617-1626, https://doi.org/10.1002/hep.26753.

[47] R. Saxena, N. Theise, Canals of Hering: recent insights and current knowledge, Semin Liver Dis. 24 (1) (2004) 43-48, https://doi.org/10.1055/s-2004-823100.

[48] N. Aizarani, A. Saviano, Sagar, L. Mailly, S. Durand, J.S. Herman, P. Pessaux, T. F. Baumert, D. Grün, A human liver cell atlas reveals heterogeneity and epithelial progenitors, Nature 572 (7768) (2019) 199-204, https://doi.org/10.1038/ s41586-019-1373-2.

[49] X. Deng, X. Zhang, W. Li, R.X. Feng, L. Li, G.R. Yi, X.N. Zhang, C. Yin, H.Y. Yu, J. P. Zhang, B. Lu, L. Hui, W.F. Xie, Chronic liver injury induces conversion of biliary epithelial cells into hepatocytes, e3, Cell Stem Cell 23 (1) (2018) 114-122, https://doi.org/10.1016/j.stem.2018.05.022.

[50] R. Manco, L.A. Clerbaux, S. Verhulst, M. Bou Nader, C. Sempoux, J. Ambroise, B. Bearzatto, J.L. Gala, Y. Horsmans, L. van Grunsven, C. Desdouets, I. Leclercq, Reactive cholangiocytes differentiate into proliferative hepatocytes with efficient DNA repair in mice with chronic liver injury, J. Hepatol. 70 (6) (2019) 1180-1191, https://doi.org/10.1016/j.jhep.2019.02.003.

[51] A. Raven, W.Y. Lu, T.Y. Man, S. Ferreira-Gonzalez, E. O’Duibhir, B.J. Dwyer, J. P. Thomson, R.R. Meehan, R. Bogorad, V. Koteliansky, Y. Kotelevtsev, C. Ffrench Constant, L. Boulter, S.J. Forbes, Cholangiocytes act as facultative liver stem cells during impaired hepatocyte regeneration, Nature 547 (7663) (2017) 350-354, https://doi.org/10.1038/nature23015.

[52] J.O. Russell, W.Y. Lu, H. Okabe, M. Abrams, M. Oertel, M. Poddar, S. Singh, S. J. Forbes, S.P. Monga, Hepatocyte-specific $\beta$-catenin deletion during severe liver injury provokes cholangiocytes to differentiate into hepatocytes, Hepatology 69 (2019) 742-759, https://doi.org/10.1002/hep.30270.

[53] L. Aloia, M.A. McKie, G. Vernaz, L. Cordero-Espinoza, N. Aleksieva, J. van den Ameele, F. Antonica, B. Font-Cunill, A. Raven, R. Aiese Cigliano, G. Belenguer, R. L. Mort, A.H. Brand, M. Zernicka-Goetz, S.J. Forbes, E.A. Miska, M. Huch, Epigenetic remodelling licences adult cholangiocytes for organoid formation and liver regeneration, Nat. Cell Biol. 21 (11) (2019) 1321-1333, https://doi.org/ 10.1038/s41556-019-0402-6.

[54] B.J. Pepe-Mooney, M.T. Dill, A. Alemany, J. Ordovas-Montanes, Y. Matsushita, A. Rao, A. Sen, M. Miyazaki, S. Anakk, P.A. Dawson, N. Ono, A.K. Shalek, A. van Oudenaarden, F.D. Camargo, Single-cell analysis of the liver epithelium reveals dynamic heterogeneity and an essential role for YAP in homeostasis and regeneration, e8, Cell Stem Cell 25 (1) (2019) 23-38, https://doi.org/10.1016/j stem.2019.04.004.

[55] L. Planas-Paz, T. Sun, M. Pikiolek, N.R. Cochran, S. Bergling, V. Orsini, Z. Yang, F. Sigoillot, J. Jetzer, M. Syed, M. Neri, S. Schuierer, L. Morelli, P.S. Hoppe, W. Schwarzer, C.M. Cobos, J.L. Alford, L. Zhang, R. Cuttat, A. Waldt, N. Carballido-Perrig, F. Nigsch, B. Kinzel, T.B. Nicholson, Y. Yang, X. Mao, L. M. Terracciano, C. Russ, J.S. Reece-Hoyes, C. Gubser Keller, A.W. Sailer, T. Bouwmeester, L.E. Greenbaum, J.J. Lugus, F. Cong, G. McAllister, G. R. Hoffman, G. Roma, J.S. Tchorz, YAP, but not RSPO-LGR4/5, signaling in biliary epithelial cells promotes a ductular reaction in response to liver injury, e10, Cell Stem Cell 25 (1) (2019) 39-53, https://doi.org/10.1016/j. stem.2019.04.005.

[56] S. Ko, J.O. Russell, L.M. Molina, S.P. Monga, Liver progenitors and adult cell plasticity in hepatic injury and repair: knowns and unknowns, Annu Rev. Pathol. 15 (2020) 23-50, https://doi.org/10.1146/annurev-pathmechdis-012419032824

[57] J.M. Llovet, J. Zucman-Rossi, E. Pikarsky, B. Sangro, M. Schwartz, M. Sherman, G. Gores, Hepatocellular carcinoma, Nat. Rev. Dis. Prim. 2 (2016) 16018, https:/ doi.org /10.1038/nrdp.2016.18.

[58] M. Huch, C. Dorrell, S.F. Boj, J.H. van Es, V.S. Li, M. van de Wetering, T. Sato, K. Hamer, N. Sasaki, M.J. Finegold, A. Haft, R.G. Vries, M. Grompe, H. Clevers, In vitro expansion of single Lgr5+ liver stem cells induced by Wnt-driven regeneration, Nature 494 (7436) (2013) 247-250, https://doi.org/10.1038/ nature11826.

[59] M. Huch, H. Gehart, R. van Boxtel, K. Hamer, F. Blokzijl, M.M. Verstegen, E. Ellis, M. van Wenum, S.A. Fuchs, J. de Ligt, M. van de Wetering, N. Sasaki, S.J. Boers, H. Kemperman, J. de Jonge, J.N. Ijzermans, E.E. Nieuwenhuis, R. Hoekstra, S. Strom, R.R. Vries, L.J. van der Laan, E. Cuppen, H. Clevers, Long-term culture of genome-stable bipotent stem cells from adult human liver, Cell 160 (1-2) (2015) 299-312, https://doi.org/10.1016/j.cell.2014.11.050.

[60] F. Sampaziotis, A.W. Justin, O.C. Tysoe, S. Sawiak, E.M. Godfrey, S.S. Upponi, R. L. Gieseck, M.C. de Brito, N.L. Berntsen, M.J. Gómez-Vázquez, D. Ortmann, L. Yiangou, A. Ross, J. Bargehr, A. Bertero, M. Zonneveld, M.T. Pedersen, M. Pawlowski, L. Valestrand, P. Madrigal, N. Georgakopoulos, N. Pirmadjid, G. M. Skeldon, J. Casey, W. Shu, P.M. Materek, K.E. Snijders, S.E. Brown, C. A. Rimland, I. Simonic, S.E. Davies, K.B. Jensen, M. Zilbauer, W. Gelson, G. J. Alexander, S. Sinha, N. Hannan, T.A. Wynn, T.H. Karlsen, E. Melum, A. E. Markaki, K. Saeb-Parsy, L. Vallier, Reconstruction of the mouse extrahepatic biliary tree using primary human extrahepatic cholangiocyte organoids, Nat. Med 23 (8) (2017) 954-963, https://doi.org/10.1038/nm.4360.
[61] C.A. Rimland, S.G. Tilson, C.M. Morell, R.A. Tomaz, W.Y. Lu, S.E. Adams, N. Georgakopoulos, F. Otaizo-Carrasquero, T.G. Myers, J.R. Ferdinand, R. L. Gieseck, F. Sampaziotis, O.C. Tysoe, A. Ross, J.M. Kraiczy, B. Wesley, D. Muraro, M. Zilbauer, G.C. Oniscu, N. Hannan, S.J. Forbes, K. Saeb-Parsy, T. A. Wynn, L. Vallier, Regional differences in human biliary tissues and corresponding in vitro-derived organoids, Hepatology 73 (1) (2021) 247-267, https://doi.org/10.1002/hep.31252.

[62] N. Lugli, I. Kamileri, A. Keogh, T. Malinka, M.E. Sarris, I. Talianidis, O. Schaad, D. Candinas, D. Stroka, T.D. Halazonetis, R-spondin 1 and noggin facilitate expansion of resident stem cells from non-damaged gallbladders, EMBO Rep. 17 (5) (2016) 769-779, https://doi.org/10.15252/embr.201642169.

[63] M. Ogawa, S. Ogawa, C.E. Bear, S. Ahmadi, S. Chin, B. Li, M. Grompe, G. Keller, B. M. Kamath, A. Ghanekar, Directed differentiation of cholangiocytes from human pluripotent stem cells, Nat. Biotechnol. 33 (8) (2015) 853-861, https://doi.org/ $10.1038 / \mathrm{nbt} .3294$.

[64] F. Sampaziotis, M.C. de Brito, P. Madrigal, A. Bertero, K. Saeb-Parsy, F. Soares, E. Schrumpf, E. Melum, T.H. Karlsen, J.A. Bradley, W.T. Gelson, S. Davies, A. Baker, A. Kaser, G.J. Alexander, N. Hannan, L. Vallier, Cholangiocytes derived from human induced pluripotent stem cells for disease modeling and drug validation, Nat. Biotechnol. 33 (8) (2015) 845-852, https://doi.org/10.1038/ nbt.3275.

[65] F. Sampaziotis, D. Muraro, O.C. Tysoe, S. Sawiak, T.E. Beach, E.M. Godfrey, S. S. Upponi, T. Brevini, B.T. Wesley, J. Garcia-Bernardo, K. Mahbubani, G. Canu, R. Gieseck, N.L. Berntsen, V.L. Mulcahy, K. Crick, C. Fear, S. Robinson, L. Swift, L. Gambardella, J. Bargehr, D. Ortmann, S.E. Brown, A. Osnato, M.P. Murphy, G. Corbett, W. Gelson, G.F. Mells, P. Humphreys, S.E. Davies, I. Amin, P. Gibbs, S. Sinha, S.A. Teichmann, A.J. Butler, T.C. See, E. Melum, C. Watson, K. SaebParsy, L. Vallier, Cholangiocyte organoids can repair bile ducts after transplantation in the human liver, Science 371 (6531) (2021) 839-846, https:// doi.org/10.1126/science.aaz6964.

[66] F. Manzano-Núñez, M.J. Arámbul-Anthony, A. Galán Albiñana, A. Leal Tassias, C. Acosta Umanzor, I. Borreda Gascó, A. Herrera, J. Forteza Vila, D.J. Burks, L A. Noon, Insulin resistance disrupts epithelial repair and niche-progenitor Fgf signaling during chronic liver injury, PLoS Biol. 17 (1) (2019), 2006972, https:// doi.org/10.1371/journal.pbio.2006972.

[67] H.M. Takase, T. Itoh, S. Ino, T. Wang, T. Koji, S. Akira, Y. Takikawa, A. Miyajima, FGF7 is a functional niche signal required for stimulation of adult liver progenitor cells that support liver regeneration, Genes Dev. 27 (2) (2013) 169-181, https:// doi.org/10.1101/gad.204776.112.

[68] L. Boulter, O. Govaere, T.G. Bird, S. Radulescu, P. Ramachandran, A. Pellicoro, R. A. Ridgway, S.S. Seo, B. Spee, N. Van Rooijen, O.J. Sansom, J.P. Iredale, S. Lowell, T. Roskams, S.J. Forbes, Macrophage-derived Wnt opposes Notch signaling to specify hepatic progenitor cell fate in chronic liver disease, Nat. Med 18 (4) (2012) 572-579, https://doi.org/10.1038/nm.2667.

[69] L. Cordero-Espinoza, A.M. Dowbaj, T.N. Kohler, B. Strauss, O. Sarlidou, G. Belenguer, C. Pacini, N.P. Martins, R. Dobie, J.R. Wilson-Kanamori, R. Butler, N. Prior, P. Serup, F. Jug, N.C. Henderson, F. Hollfelder, M. Huch, Dynamic cell contacts between periportal mesenchyme and ductal epithelium act as a rheostat for liver cell proliferation, Cell Stem Cell (2021), https://doi.org/10.1016/j. stem.2021.07.002

[70] R. Dobie, J.R. Wilson-Kanamori, B. Henderson, J.R. Smith, K.P. Matchett, J. R. Portman, K. Wallenborg, S. Picelli, A. Zagorska, S.V. Pendem, T.E. Hudson, M. M. Wu, G.R. Budas, D.G. Breckenridge, E.M. Harrison, D.J. Mole, S.J. Wigmore, P. Ramachandran, C.P. Ponting, S.A. Teichmann, J.C. Marioni, N.C. Henderson, Single-cell transcriptomics uncovers zonation of function in the mesenchyme during liver fibrosis, e8, Cell Rep. 29 (7) (2019) 1832-1847, https://doi.org/ 10.1016/j.celrep.2019.10.024.

[71] S.L. Friedman, Hepatic stellate cells: protean, multifunctional, and enigmatic cells of the liver, Physiol. Rev. 88 (1) (2008) 125-172, https://doi.org/10.1152/ physrev.00013.2007.

[72] C. Yin, K.J. Evason, K. Asahina, D.Y. Stainier, Hepatic stellate cells in live development, regeneration, and cancer, J. Clin. Investig. 123 (5) (2013) 1902-1910, https://doi.org/10.1172/JCI66369.

[73] P. Ramachandran, R. Dobie, J.R. Wilson-Kanamori, E.F. Dora, B. Henderson, N. T. Luu, J.R. Portman, K.P. Matchett, M. Brice, J.A. Marwick, R.S. Taylor, M. Efremova, R. Vento-Tormo, N.O. Carragher, T.J. Kendall, J.A. Fallowfield, E. M. Harrison, D.J. Mole, S.J. Wigmore, P.N. Newsome, C.J. Weston, J.P. Iredale, F. Tacke, J.W. Pollard, C.P. Ponting, J.C. Marioni, S.A. Teichmann, N. C. Henderson, Resolving the fibrotic niche of human liver cirrhosis at single-cell level, Nature 575 (7783) (2019) 512-518, https://doi.org/10.1038/s41586-0191631-3.

[74] S.A. MacParland, J.C. Liu, X.Z. Ma, B.T. Innes, A.M. Bartczak, B.K. Gage, J. Manuel, N. Khuu, J. Echeverri, I. Linares, R. Gupta, M.L. Cheng, L.Y. Liu, D. Camat, S.W. Chung, R.K. Seliga, Z. Shao, E. Lee, S. Ogawa, M. Ogawa, M. D. Wilson, J.E. Fish, M. Selzner, A. Ghanekar, D. Grant, P. Greig, G. Sapisochin, N. Selzner, N. Winegarden, O. Adeyi, G. Keller, G.D. Bader, I.D. McGilvray, Single cell RNA sequencing of human liver reveals distinct intrahepatic macrophage populations, Nat. Commun. 9 (1) (2018) 4383, https://doi.org/10.1038/s41467018-06318-7.

[75] K.B. Halpern, R. Shenhav, H. Massalha, B. Toth, A. Egozi, E.E. Massasa, C. Medgalia, E. David, A. Giladi, A.E. Moor, Z. Porat, I. Amit, S. Itzkovitz, Pairedcell sequencing enables spatial gene expression mapping of liver endothelial cells, Nat. Biotechnol. 36 (10) (2018) 962-970, https://doi.org/10.1038/nbt.4231.

[76] I. Mederacke, C.C. Hsu, J.S. Troeger, P. Huebener, X. Mu, D.H. Dapito, J. P. Pradere, R.F. Schwabe, Fate tracing reveals hepatic stellate cells as dominant 
contributors to liver fibrosis independent of its aetiology, Nat. Commun. 4 (2013) 2823, https://doi.org/10.1038/ncomms3823.

[77] E. Roeb, Matrix metalloproteinases and liver fibrosis (translational aspects), Matrix Biol. 68-69 (2018) 463-473, https://doi.org/10.1016/j. matbio.2017.12.012.

[78] L. Cordero-Espinoza, M. Huch, The balancing act of the liver: tissue regeneration versus fibrosis, J. Clin. Investig. 128 (1) (2018) 85-96, https://doi.org/10.1172/ JCI93562.

[79] M. Zhu, T. Lu, Y. Jia, X. Luo, P. Gopal, L. Li, M. Odewole, V. Renteria, A.G. Singal, Y. Jang, K. Ge, S.C. Wang, M. Sorouri, J.R. Parekh, M.P. MacConmara, A.C. Yopp, T. Wang, H. Zhu, Somatic mutations increase hepatic clonal fitness and regeneration in chronic liver disease, e12, Cell 177 (3) (2019) 608-621, https:// doi.org/10.1016/j.cell.2019.03.026.

[80] S.F. Brunner, N.D. Roberts, L.A. Wylie, L. Moore, S.J. Aitken, S.E. Davies, M. A. Sanders, P. Ellis, C. Alder, Y. Hooks, F. Abascal, M.R. Stratton, I. Martincorena, M. Hoare, P.J. Campbell, Somatic mutations and clonal dynamics in healthy and cirrhotic human liver, Nature 574 (7779) (2019) 538-542, https://doi.org/ 10.1038/s41586-019-1670-9.

[81] M.M. Richardson, J.R. Jonsson, E.E. Powell, E.M. Brunt, B.A. NeuschwanderTetri, P.S. Bhathal, J.B. Dixon, M.D. Weltman, H. Tilg, A.R. Moschen, D. M. Purdie, A.J. Demetris, A.D. Clouston, Progressive fibrosis in nonalcoholic steatohepatitis: association with altered regeneration and a ductular reaction, Gastroenterology 133 (1) (2007) 80-90, https://doi.org/10.1053/j. gastro.2007.05.012.

[82] T. Roskams, S.Q. Yang, A. Koteish, A. Durnez, R. DeVos, X. Huang, R. Achten, C. Verslype, A.M. Diehl, Oxidative stress and oval cell accumulation in mice and humans with alcoholic and nonalcoholic fatty liver disease, Am. J. Pathol. 163 (4) (2003) 1301-1311, https://doi.org/10.1016/S0002-9440(10)63489-X.

[83] A.E. Stueck, I.R. Wanless, Hepatocyte buds derived from progenitor cells repopulate regions of parenchymal extinction in human cirrhosis, Hepatology 61 (5) (2015) 1696-1707, https://doi.org/10.1002/hep.27706.

[84] G. Sorrentino, S. Rezakhani, E. Yildiz, S. Nuciforo, M.H. Heim, M.P. Lutolf, K. Schoonjans, Mechano-modulatory synthetic niches for liver organoid derivation, Nat. Commun. 11 (1) (2020) 3416, https://doi.org/10.1038/s41467 020-17161-0.

[85] D.H. Wilson, E.J. Jarman, R.P. Mellin, M.L. Wilson, S.H. Waddell, P. Tsokkou, N. T. Younger, A. Raven, S.R. Bhalla, A. Noll, S.W. Olde Damink, F.G. Schaap, P. Chen, D.O. Bates, J.M. Banales, C.H. Dean, D.J. Henderson, O.J. Sansom, T. J. Kendall, L. Boulter, Non-canonical Wnt signalling regulates scarring in biliary disease via the planar cell polarity receptors, Nat. Commun. 11 (1) (2020) 445 , https://doi.org/10.1038/s41467-020-14283-3.

[86] M. Mooring, B.H. Fowl, S. Lum, Y. Liu, K. Yao, S. Softic, R. Kirchner, A. Bernstein, A.D. Singhi, D.G. Jay, C.R. Kahn, F.D. Camargo, D. Yimlamai, Hepatocyte stress increases expression of yes-associated protein and transcriptional coactivator with PDZ-binding motif in hepatocytes to promote parenchymal inflammation and fibrosis, Hepatology 71 (5) (2020) 1813-1830, https://doi.org/10.1002/ hep.30928.

[87] S. Dupont, L. Morsut, M. Aragona, E. Enzo, S. Giulitti, M. Cordenonsi, F. Zanconato, J. Le Digabel, M. Forcato, S. Bicciato, N. Elvassore, S. Piccolo, Role of YAP/TAZ in mechanotransduction, Nature 474 (7350) (2011) 179-183, https://doi.org/10.1038/nature10137.

[88] I. Mannaerts, S.B. Leite, S. Verhulst, S. Claerhout, N. Eysackers, L.F. Thoen, A. Hoorens, H. Reynaert, G. Halder, L.A. van Grunsven, The Hippo pathway effector YAP controls mouse hepatic stellate cell activation, J. Hepatol. 63 (3) (2015) 679-688, https://doi.org/10.1016/j.jhep.2015.04.011.

[89] G. Sorrentino, N. Ruggeri, V. Specchia, M. Cordenonsi, M. Mano, S. Dupont, A. Manfrin, E. Ingallina, R. Sommaggio, S. Piazza, A. Rosato, S. Piccolo, G. De Sal, Metabolic control of YAP and TAZ by the mevalonate pathway, Nat. Cell Biol. 16 (4) (2014) 357-366, https://doi.org/10.1038/ncb2936.

[90] S.H. Patel, F.D. Camargo, D. Yimlamai, Hippo signaling in the liver regulates organ size, cell fate, and carcinogenesis, Gastroenterology 152 (3) (2017) 533-545, https://doi.org/10.1053/j.gastro.2016.10.047.

[91] F.D. Camargo, S. Gokhale, J.B. Johnnidis, D. Fu, G.W. Bell, R. Jaenisch, T. R. Brummelkamp, YAP1 increases organ size and expands undifferentiated progenitor cells, Curr. Biol. 17 (23) (2007) 2054-2060, https://doi.org/10.1016/ j.cub.2007.10.039.

[92] J. Dong, G. Feldmann, J. Huang, S. Wu, N. Zhang, S.A. Comerford, M.F. Gayyed, R.A. Anders, A. Maitra, D. Pan, Elucidation of a universal size-control mechanism in Drosophila and mammals, Cell 130 (6) (2007) 1120-1133, https://doi.org/ 10.1016/j.cell.2007.07.019.

[93] A. Perra, M.A. Kowalik, E. Ghiso, G.M. Ledda-Columbano, L. Di Tommaso, M. M. Angioni, C. Raschioni, E. Testore, M. Roncalli, S. Giordano, A. Columbano,
YAP activation is an early event and a potential therapeutic target in liver cancer development, J. Hepatol. 61 (5) (2014) 1088-1096, https://doi.org/10.1016/j. jhep.2014.06.033.

[94] K. Meyer, H. Morales-Navarrete, S. Seifert, M. Wilsch-Braeuninger, U. Dahmen, E. M. Tanaka, L. Brusch, Y. Kalaidzidis, M. Zerial, Bile canaliculi remodeling activates YAP via the actin cytoskeleton during liver regeneration, Mol. Syst. Biol. 16 (2) (2020) 8985, https://doi.org/10.15252/msb.20198985.

[95] W. Li, L. Yang, Q. He, C. Hu, L. Zhu, X. Ma, X. Ma, S. Bao, L. Li, Y. Chen, X. Deng, X. Zhang, J. Cen, L. Zhang, Z. Wang, W.F. Xie, H. Li, Y. Li, L. Hui, A homeostatic arid1a-dependent permissive chromatin state licenses hepatocyte responsiveness to liver-injury-associated YAP signaling, e5, Cell Stem Cell 25 (1) (2019) 54-68, https://doi.org/10.1016/j.stem.2019.06.008.

[96] K.S. Tummala, M. Brandt, A. Teijeiro, O. Graña, R.F. Schwabe, C. Perna, N. Djouder, Hepatocellular carcinomas originate predominantly from hepatocytes and benign lesions from hepatic progenitor cells, Cell Rep. 19 (3) (2017) 584-600, https://doi.org/10.1016/j.celrep.2017.03.059.

[97] K.D. Rasmussen, K. Helin, Role of TET enzymes in DNA methylation, development, and cancer, Genes Dev. 30 (7) (2016) 733-750, https://doi.org/ 10.1101/gad.276568.115.

[98] A.G. Cox, K.L. Hwang, K.K. Brown, K. Evason, S. Beltz, A. Tsomides, K. O'Connor, G.G. Galli, D. Yimlamai, S. Chhangawala, M. Yuan, E.C. Lien, J. Wucherpfennig, S. Nissim, A. Minami, D.E. Cohen, F.D. Camargo, J.M. Asara, Y. Houvras, D. Stainier, W. Goessling, Yap reprograms glutamine metabolism to increase nucleotide biosynthesis and enable liver growth, Nat. Cell Biol. 18 (8) (2016) 886-896, https://doi.org/10.1038/ncb3389.

[99] X. Zhang, Y. Li, Y. Ma, L. Yang, T. Wang, X. Meng, Z. Zong, X. Sun, X. Hua, H. Li, Yes-associated protein (YAP) binds to HIF-1 $\alpha$ and sustains HIF-1 $\alpha$ protein stability to promote hepatocellular carcinoma cell glycolysis under hypoxic stress, J. Exp. Clin. Cancer Res. 37 (1) (2018) 216, https://doi.org/10.1186/s13046-018-0892-

[100] E. Enzo, G. Santinon, A. Pocaterra, M. Aragona, S. Bresolin, M. Forcato, D. Grifoni, A. Pession, F. Zanconato, G. Guzzo, S. Bicciato, S. Dupont, Aerobic glycolysis tunes YAP/TAZ transcriptional activity, EMBO J. 34 (10) (2015) 1349-1370, https://doi.org/10.15252/embj.201490379.

[101] A. Page, P. Paoli, E. Moran Salvador, S. White, J. French, J. Mann, Hepatic stellate cell transdifferentiation involves genome-wide remodeling of the DNA methylation landscape, J. Hepatol. 64 (3) (2016) 661-673, https://doi.org/ 10.1016/j.jhep.2015.11.024

[102] T. Hardy, D.A. Mann, Epigenetics in liver disease: from biology to therapeutics, Gut 65 (11) (2016) 1895-1905, https://doi.org/10.1136/gutinl-2015-311292.

[103] L. Broutier, G. Mastrogiovanni, M.M. Verstegen, H.E. Francies, L.M. Gavarró, C. R. Bradshaw, G.E. Allen, R. Arnes-Benito, O. Sidorova, M.P. Gaspersz, N. Georgakopoulos, B.K. Koo, S. Dietmann, S.E. Davies, R.K. Praseedom, R. Lieshout, J. IJzermans, S.J. Wigmore, K. Saeb-Parsy, M.J. Garnett, L.J. van der Laan, M. Huch, Human primary liver cancer-derived organoid cultures for disease modeling and drug screening, Nat. Med. 23 (12) (2017) 1424-1435, https://doi. org $/ 10.1038 / \mathrm{nm} .4438$

[104] S. Ye, J.W.B. Boeter, M. Mihajlovic, F.G. Steenbeek, M.E. Wolferen, L. A. Oosterhoff, A. Marsee, M. Caiazzo, L.J.W. Laan, L.C. Penning, T. Vermonden, B. Spee, K. Schneeberger, A chemically defined hydrogel for human liver organoid culture, Adv. Funct. Mater. 30 (48) (2020), 2000893, https://doi.org/10.1002/ adfm.202000893.

[105] F. Moroni, B.J. Dwyer, C. Graham, C. Pass, L. Bailey, L. Ritchie, D. Mitchell, A. Glover, A. Laurie, S. Doig, E. Hargreaves, A.R. Fraser, M.L. Turner, J. Campbell, N. McGowan, J. Barry, J.K. Moore, P.C. Hayes, D.J. Leeming, M.J. Nielsen, K. Musa, J.A. Fallowfield, S.J. Forbes, Safety profile of autologous macrophage therapy for liver cirrhosis, Nat. Med. 25 (10) (2019) 1560-1565, https://doi.org/ 10.1038/s41591-019-0599-8.

[106] L. Campana, H. Esser, M. Huch, S. Forbes, Liver regeneration and inflammation: from fundamental science to clinical applications, Nat. Rev. Mol. Cell Biol. 22 (2021) 608-624, https://doi.org/10.1038/s41580-021-00373-7.

[107] M. Okabe, Y. Tsukahara, M. Tanaka, K. Suzuki, S. Saito, Y. Kamiya, T. Tsujimura, K. Nakamura, A. Miyajima, Potential hepatic stem cells reside in EpCAM+ cells of normal and injured mouse liver, Development 136 (11) (2009) 1951-1960, https://doi.org/10.1242/dev.031369.

[108] W.-Y. Lu, T.G. Bird, L. Boulter, A. Tsuchiya, A.M. Cole, T. Hay, R.V. Guest, D. Wojtacha, T.Y. Man, A. Mackinnon, R. Ridgway, T. Kendall, M.J. Williams, T. Jamieson, A. Raven, D.C. Hay, J.P. Iredale, A.R. Clarke, O.J. Sansom, S. J. Forbes, Hepatic progenitor cells of biliary origin with liver repopulation capacity, Nat. Cell Biol. 17 (8) (2015) 971-983, https://doi.org/10.1038/ ncb3203. 